\title{
A Randomized Trial of Antimicrobial Prophylaxis in Patients Undergoing Medical Thoracoscopy (APT)
}

\author{
Sahajal Dhooria ${ }^{a}$ Inderpaul Singh Sehgala Kuruswamy Thurai Prasad ${ }^{a}$ \\ Amanjit Bal $^{\mathrm{b}} \quad$ Ashutosh Nath Aggarwal $^{\mathrm{a}} \quad$ Digambar Behera $^{\mathrm{a}} \quad$ Ritesh Agarwal $^{\mathrm{a}}$ \\ Departments of a Pulmonary Medicine and ${ }^{\mathrm{b}}$ Histopathology, Postgraduate Institute of Medical Education and \\ Research (PGIMER), Chandigarh, India
}

For editorial comment see p. 176

\section{Keywords}

Antibiotics · Pleuroscopy · Thoracic surgery · Empyema ·

Pleural biopsy · Pleural effusion

\begin{abstract}
Background: There is no data on the role of prophylactic antibiotics in patients undergoing medical thoracoscopy. Objective: In this study, we evaluated the efficacy and safety of a single dose of intravenous cefazolin in subjects undergoing medical thoracoscopy. Methods: Subjects undergoing medical thoracoscopy were randomized 1:1 to receive either intravenous cefazolin $2 \mathrm{~g}$ (antibiotic group) or intravenous saline (control group). The primary outcome was the incidence of infections (surgical site infections and empyema) in the study groups, while the secondary outcomes were complications related to intravenous antibiotics. Results: Of the 121 subjects screened, 100 (mean age \pm SD: $52.2 \pm 15.2$ years; 38 [38\%] women) were randomized to the study groups. The incidence of postprocedural infections was not different between the antibiotic and the control group (4 [8\%] vs. 6 [12\%], $p=0.28)$. Surgical site infection occurred in 1 subject $(2 \%)$ in the antibiotic group and 3 subjects (6\%) in the saline group ( $p=0.62$ ); empyema occurred in 3 subjects $(6 \%)$ in each group $(p=1.00)$. There was no association between age, comorbid illness (diabetes mellitus or chronic kidney
\end{abstract}

\section{KARGER}

(C) 2017 S. Karger AG, Basel

E-Mail karger@karger.com

www.karger.com/res disease), study group allocation, type of thoracoscope used, duration of procedure, histological diagnosis (benign or malignant), and the occurrence of infections in the postprocedural period. Conclusion: The use of a single dose of cefazolin prior to medical thoracoscopy was not associated with a reduction in the occurrence of postprocedural infection.

(c) 2017 S. Karger AG, Basel

\section{Introduction}

Medical thoracoscopy is the preferred procedure for performing pleural biopsy in patients with pleural effusions that remain undiagnosed after pleural fluid analysis $[1,2]$. Unlike video-assisted thoracoscopic surgery that is performed under general anesthesia and single lung ventilation, medical thoracoscopy is performed under conscious sedation and local anesthesia [3]. Medical thoracoscopy is generally a safe procedure, albeit with a small risk of complications [4]. Surgical site infections and empyema are among the important complications of the procedure [4].

Several studies have tested the effectiveness of antimicrobial drugs for the prevention of postoperative infections after noncardiac thoracic surgery [5-7]. In a previous study, a single preoperative dose of $1 \mathrm{~g}$ of cefazolin

Prof. Dr. Ritesh Agarwal, MD, DM

Department of Pulmonary Medicine

Postgraduate Institute of Medical Education and Research, Sector-12

Chandigarh 160012 (India)

E-Mail agarwal.ritesh@ outlook.in 
was found to be effective in reducing the wound infection rate in noncardiac thoracic surgery [5]. In another study, a single dose of $1.5 \mathrm{~g}$ of cefuroxime given preoperatively did not reduce the incidence of postoperative infection in patients undergoing thoracic surgery as compared to no antibiotic use [7]. A clinical practice guideline for antimicrobial prophylaxis in surgery recommends a single dose of cefazolin or ampicillin-sulbactam in patients undergoing thoracic surgical procedures [8].

There is no information, however, on the utility of prophylactic antibiotics in patients undergoing medical thoracoscopy for undiagnosed pleural effusions. Several large series on medical thoracoscopy do not mention any use of prophylactic antibiotics with the procedure [9-13]. A recent guideline on medical thoracoscopy cites the absence of scientific evidence in this area and suggests the prophylactic use of antibiotics only in high-risk populations such as those with asplenia or prosthetic heart valves [1]. Our center is a tertiary care referral hospital; the majority of our patients are referred to our center late in the course of their illness [14]. In fact, most patients have had several thoracenteses, and many patients have pleural adhesions. We have observed a significant incidence of postprocedural infections (7.8\%) in a previous study [15]. We hypothesized that a single dose of intravenous cefazolin $2 \mathrm{~g}$ would reduce the rate of infectious complications following thoracoscopy. In this study, we assessed the efficacy and safety of the prophylactic use of a single dose of cefazolin in preventing postprocedural infectious complications in subjects undergoing medical thoracoscopy.

\section{Subjects and Methods}

This was a randomized, controlled trial conducted in the Thoracic Endoscopy Suite at the Department of Pulmonary Medicine, PGIMER, Chandigarh, India. The study protocol was approved by the Institute Ethics Committee, and written informed consent was obtained from all study subjects. The study is registered at www. clinicaltrials.gov (NCT02446782).

\section{Study Subjects}

Consecutive subjects aged $\geq 18$ years undergoing medical thoracoscopy (rigid or semirigid) for pleural biopsy were eligible for inclusion in the study. Subjects with any of the following criteria were excluded from the study: (i) age $\geq 80$ years; (ii) pulse oximetric saturation $<92 \%$ despite $\mathrm{F}_{\mathrm{IO} 2}$ of 0.3 ; (iii) hemodynamic instability; (iv) myocardial infarction or unstable angina in the preceding 6 weeks; (v) lack of pleural space due to adhesions; (vi) uncorrected coagulopathy; (vii) pre-existing pleural space infection; (viii) administration of any antibiotic in the previous 7 days; (ix) presence of an intercostal drainage tube, and ( $\mathrm{x}$ ) failure to provide informed consent.

\section{Study Procedures}

Subjects referred for medical thoracoscopy were initially evaluated with thoracic ultrasonography. The pleural space was assessed for the presence of pleural fluid and the presence or absence of any septations. The site of incision for the procedure was marked using ultrasonography. If significant adhesions were visualized, the patients underwent rigid thoracoscopy; in the absence of septations, semirigid thoracoscopy was performed [16].

\section{Randomization}

The patients were randomized in a 1:1 ratio to the antibiotic or the control group using a computer-generated randomization sequence (in blocks of 10); the group assignments were placed in opaque, sealed envelopes. In the antibiotic group, a single dose of intravenous cefazolin $2 \mathrm{~g}$ was administered over $10 \mathrm{~min}$, dissolved in $100 \mathrm{~mL}$ of normal saline between 15 and $30 \mathrm{~min}$ before the incision. This was preceded by an intradermal test dose to check for hypersensitivity to the drug. If hypersensitivity to the drug was present, the patient could receive a single intravenous dose of 900 $\mathrm{mg}$ of clindamycin. In the control group, $100 \mathrm{~mL}$ of normal saline was administered intravenously over a period of $10 \mathrm{~min}$ between 15 and $30 \mathrm{~min}$ before the incision. The study treatments were administered by a nurse before the subjects entered the thoracic endoscopy suite. The operator and the investigators were blinded to the study group allocation.

\section{Thoracoscopy Procedure}

Thoracoscopy was performed in the thoracic endoscopy suite on a spontaneously breathing subject (fasting for $8 \mathrm{~h}$ ) under conscious sedation (using midazolam, pentazocine, and tramadol) observing complete aseptic precautions $[11,15]$. A semirigid thoracoscope (LTF-160; Olympus, Tokyo, Japan) or a rigid thoracoscope (Richard Wolf GmbH, Knittlingen, Germany) was used. Blood pressure was monitored every $10 \mathrm{~min}$, whereas oxygen saturation, heart rate, and heart rhythm were monitored continuously. Supplemental oxygen was administered via an air-entrainment mask. The subject was placed in the lateral decubitus position with the involved side upward. The surgical area was cleaned with $2 \%$ povidone-iodine and was left to dry for $3 \mathrm{~min}$. After placing sterile surgical drapes, the site was infiltrated with $2 \%$ lidocaine, and a 1$2 \mathrm{~cm}$ (rarely up to $3 \mathrm{~cm}$ ) skin incision was made. Blunt dissection was used to enter the pleural space. The trocar supplied with the respective thoracoscope was inserted prior to the introduction of the thoracoscope. Pleural fluid was aspirated and air was allowed to enter the pleural space.

The parietal, visceral, and diaphragmatic pleura were inspected and biopsies were taken under direct vision from all suspect areas of the parietal pleura $[15,17]$. If adhesions were present, adhesiolysis was performed using the biopsy forceps. Pleurodesis using talc poudrage was performed wherever indicated. A 24-28 Fr intercostal drainage tube was inserted before wound closure to evacuate air and fluid. The subjects were admitted to the respiratory diseases ward after the procedure. A chest radiograph was obtained $3 \mathrm{~h}$ after the procedure. The intercostal tube was removed once the lung expanded, the drainage decreased to $\leq 50 \mathrm{~mL} /$ day, and the effluent was a clear fluid.

\section{Outcomes}

The demographic characteristics, procedure details, and the histological diagnosis of the patients were recorded. The patients 
Table 1. Baseline characteristics, procedure details, and histological diagnoses of the study population

\begin{tabular}{|c|c|c|c|c|}
\hline & $\begin{array}{l}\text { Antibiotic group } \\
(n=50)\end{array}$ & $\begin{array}{l}\text { Control group } \\
(n=50)\end{array}$ & $\begin{array}{l}\text { Total } \\
(n=100)\end{array}$ & $p$ value \\
\hline \multicolumn{5}{|l|}{ Baseline characteristics } \\
\hline Age, years & $53.4 \pm 14.7$ & $51.0 \pm 15.7$ & $52.2 \pm 15.2$ & 0.43 \\
\hline Female gender & $22(44)$ & $16(32)$ & $38(38)$ & 0.30 \\
\hline Duration of symptoms, months & $2(1-4)$ & $2(1-3)$ & $2(1-3)$ & 0.94 \\
\hline \multicolumn{5}{|l|}{ Comorbidities } \\
\hline Hypertension & $4(8)$ & $5(10)$ & $9(9)$ & 1.00 \\
\hline Diabetes mellitus & $3(6)$ & $3(6)$ & $6(6)$ & 1.00 \\
\hline Chronic kidney disease & $6(12)$ & $1(2)$ & $7(7)$ & 0.11 \\
\hline Chronic liver disease & $1(2)$ & 0 & $1(1)$ & 1.00 \\
\hline Coronary artery disease & $2(4)$ & $1(2)$ & $3(3)$ & 1.00 \\
\hline \multicolumn{5}{|l|}{ Suspected clinical diagnosis } \\
\hline Tuberculosis & $22(44)$ & $21(42)$ & $43(43)$ & 0.78 \\
\hline Metastatic malignancy & $26(52)$ & $28(56)$ & $54(54)$ & \\
\hline Lymphoma & $1(2)$ & $1(2)$ & $2(2)$ & \\
\hline Hypereosinophilic syndrome & $1(2)$ & 0 & $1(1)$ & \\
\hline \multicolumn{5}{|l|}{ Procedure details } \\
\hline \multicolumn{5}{|l|}{ Side of effusion } \\
\hline Right & $28(56)$ & $23(46)$ & $51(51)$ & 0.32 \\
\hline Left & $18(36)$ & $25(50)$ & $43(43)$ & \\
\hline Bilateral & $4(8)$ & $2(4)$ & $6(6)$ & \\
\hline \multicolumn{5}{|l|}{ Size of effusion } \\
\hline Mild & $2(4)$ & $2(4)$ & $4(4)$ & 0.21 \\
\hline Moderate & $30(60)$ & $39(78)$ & $69(69)$ & \\
\hline Large & $6(12)$ & $2(4)$ & $8(8)$ & \\
\hline Massive & $12(24)$ & $7(14)$ & $19(19)$ & \\
\hline \multicolumn{5}{|l|}{ Type of thoracoscope used } \\
\hline Rigid & $30(60)$ & $35(70)$ & $65(65)$ & 0.40 \\
\hline Semirigid & $20(40)$ & $15(30)$ & $35(35)$ & \\
\hline Duration of procedure, min & $41.5 \pm 16.9$ & $39.5 \pm 13.0$ & $40.4 \pm 14.9$ & 0.59 \\
\hline Adhesiolysis & $17(34)$ & $23(46)$ & $40(40)$ & 0.31 \\
\hline Talc pleurodesis & $3(6)$ & $3(6)$ & $6(6)$ & 1.00 \\
\hline \multicolumn{5}{|l|}{ Histological diagnosis } \\
\hline Malignancy & $17(34.7)$ & $18(37.5)$ & $35(36.1)$ & 0.57 \\
\hline Tuberculosis & $15(30.6)$ & $15(31.3)$ & $30(30.9)$ & \\
\hline Nonspecific inflammation & $17(34.7)$ & $12(25.0)$ & $29(29.9)$ & \\
\hline Amyloidosis & 0 & $1(2.1)$ & $1(1)$ & \\
\hline Nocardiosis & 0 & $1(2.1)$ & $1(1)$ & \\
\hline Sarcoidosis & 0 & $1(2.1)$ & $1(1)$ & \\
\hline
\end{tabular}

All values are mean \pm standard deviation, median (interquartile range), or number (percentage).

were followed up for a minimum of 1 month or until 2 weeks after the intercostal drainage tube was removed, whichever was later. The primary outcome was the occurrence of postprocedural infection which included: (a) surgical site infection as indicated by the development of a purulent discharge from the surgical site; or (b) empyema as indicated by pus in the pleural cavity with/without the growth of a microorganism on cultures of the pleural fluid drained by the intercostal tube on the side of the procedure. The secondary outcomes were any adverse effects arising out of the administration of the antibiotic.

Antimicrobial Prophylaxis in Thoracoscopy

\section{Statistical Methods}

Data were analyzed using the statistical package SPSS (SPSS version 22, for Windows; IBM SPSS Inc., Chicago, IL, USA). Data are presented in a descriptive fashion as mean $\pm(\mathrm{SD})$, median (interquartile range [IQR]), or number (percentage). The normalcy of distribution was evaluated using the Shapiro-Wilk test. The differences between continuous variables were analyzed using the Mann-Whitney U test if not normally distributed and the Student $t$ test if normally distributed. The differences between categorical variables were analyzed using Fisher's exact test. Univariate and

Respiration 2017;94:207-215

DOI: $10.1159 / 000477259$ 
multivariate logistic regression analyses were performed to assess the factors associated with the occurrence of postprocedural infection.

\section{Results}

Of the 121 subjects screened during the study period, 100 were randomized to the study groups. The reasons for exclusion were the presence of an intercostal drainage tube in situ $(n=16)$, having received antibiotics in the previous 7 days $(n=3)$, and the presence of an intrapleural foreign body $(n=2$; broken thoracentesis needles in both cases). The mean age (SD) of the randomized subjects was $52.2(15.2)$ years; 38 (38\%) were women (Table 1). Six subjects had diabetes mellitus, and seven had chronic kidney disease. Rigid thoracoscopy was performed in 65 subjects, while the remaining 35 patients underwent semirigid thoracoscopy. A pleural biopsy specimen could be obtained successfully in 97 subjects. Malignancy (36.1\%) and tuberculosis (30.9\%) were the most common histological diagnoses. All subjects in the antibiotic group received intravenous cefazolin; none had cutaneous hypersensitivity to the drug.

Ten subjects developed postprocedural infections (Table 2) and the occurrence was not different between the 2 groups (antibiotic vs. control group, 4 [8\%] vs. 6 [12\%]; $p=0.28$ ). Surgical site infection occurred in 1 subject $(2 \%)$ in the antibiotic group and 3 subjects $(6 \%)$ in the control group; empyema occurred in 3 subjects (6\%) in each group (Table 2). In 1 subject, culture of the pleural fluid grew Staphylococcus aureus; in another subject, there was a growth of Pseudomonas aeruginosa. Both were administered antibiotics according to the sensitivity pattern and responded. The cultures were sterile in the other subjects; these patients received empiric antibiotics. The median duration (IQR) of postprocedural intercostal tube drainage was $4(2-10)$ and $3(2-10)$ days in the antibiotic and control groups, respectively $(p=0.66)$. Subjects who developed infections had a significantly longer median duration of intercostal drainage as compared to those who did not develop infections (23 [7-52] vs. 3 [2-9] days, $p=0.002$ ).

Three subjects in the antibiotic group and 2 subjects in the control group developed chills during the infusion. The infusion was stopped temporarily, intravenous promethazine was administered, and the infusion was restarted at a slower rate. All of the patients recovered completely and received the entire infusion. There were other complications, such as prolonged air leak (3 vs. 2
Table 2. Infectious and noninfectious complications in the study subjects

\begin{tabular}{lllll}
\hline Complications & $\begin{array}{l}\text { Antibiotic } \\
\text { group } \\
(n=50)\end{array}$ & $\begin{array}{l}\text { Control } \\
\text { group } \\
(n=50)\end{array}$ & $\begin{array}{l}\text { Total } \\
(n=100)\end{array}$ & $\begin{array}{l}p \\
\text { value }\end{array}$ \\
\hline $\begin{array}{l}\text { Primary outcomes } \\
\quad \text { Any infection }\end{array}$ & $4(8)$ & $6(12)$ & $10(10)$ & 0.74 \\
$\quad \begin{array}{l}\text { Surgical site infection } \\
\quad 1(2)\end{array}$ & $3(6)$ & $4(4)$ & 0.62 \\
$\quad \begin{array}{l}\text { Empyema } \\
\text { Secondary outcomes }\end{array}$ & $3(6)$ & $3(6)$ & $6(6)$ & 1.00 \\
$\quad$ Chills during infusion & $3(6)$ & $2(4)$ & $5(5)$ & 0.50 \\
\hline
\end{tabular}

All values represent number (percentage).

in the antibiotic and control groups, respectively; $p=$ 0.50 ) and pleural hemorrhage (1 in each group), which were not significantly different between the 2 groups. Two deaths occurred during follow-up (1 in each group). One subject (in the antibiotic group) developed re-expansion pulmonary edema and hypotension. He was managed in the intensive care unit with mechanical ventilation and vasopressors. He developed refractory shock and hypoxemia and succumbed to his illness within $24 \mathrm{~h}$. He was diagnosed to have non-Hodgkin's lymphoma. The other subject (in the control group) had sudden-onset breathlessness at home 3 days after the procedure and expired; the probable cause of death was pulmonary embolism. She was diagnosed to have metastatic adenocarcinoma.

None of the suspected factors including age, presence of comorbid illness (diabetes mellitus or chronic kidney disease), study group allocation, type of thoracoscope used, duration of procedure, and histological diagnosis (benign or malignant) was significantly different between the group with infections $(n=10)$ and those without infections $(n=90)$. In a multivariate logistic regression analysis, none of these factors was associated with the risk of infection in the postprocedural period (Table 3).

\section{Discussion}

The results of this study suggest that a single dose of cefazolin does not reduce the occurrence of postprocedural infections in patients undergoing medical thoracoscopy. To our knowledge, this is the first study evaluating the use of a prophylactic antibiotic during medical thoracoscopy.
Dhooria/Sehgal/Prasad/Bal/Aggarwal/ Behera/Agarwal 
Table 3. Comparison of the study subjects with and those without postprocedural infections

\begin{tabular}{|c|c|c|c|c|}
\hline Characteristics & $\begin{array}{l}\text { Any infection } \\
(n=10)\end{array}$ & $\begin{array}{l}\text { No infection } \\
(n=90)\end{array}$ & $\begin{array}{l}\text { Crude odds ratio } \\
(95 \% \mathrm{CI})^{*}\end{array}$ & $\begin{array}{l}\text { Adjusted odds ratio } \\
(95 \% \mathrm{CI})^{*}\end{array}$ \\
\hline Age, years & $57.1 \pm 12.5$ & $51.7 \pm 15.4$ & $1.03(0.98-1.07)$ & $1.04(0.98-1.11)$ \\
\hline \multicolumn{5}{|l|}{ Comorbidity ${ }^{\mathrm{a}}$} \\
\hline Present & $1(7.7)$ & $12(92.3)$ & $0.72(0.08-6.22)$ & $0.60(0.05-7.01)$ \\
\hline Absent & $9(10.3)$ & $78(89.7)$ & & \\
\hline \multicolumn{5}{|l|}{ Study group } \\
\hline Antibiotic group & $4(8.0)$ & $46(92.0)$ & $0.64(0.17-2.41)$ & $0.61(0.12-3.04)$ \\
\hline Control group & $6(12.0)$ & $44(88.0)$ & & \\
\hline \multicolumn{5}{|l|}{ Type of thoracoscope used } \\
\hline Rigid & $9(13.8)$ & $56(86.2)$ & $5.46(0.66-45.05)$ & $5.24(0.56-49.21)$ \\
\hline Semirigid & $1(2.9)$ & $34(97.1)$ & & \\
\hline Duration of procedure, min & $37.3 \pm 5.9$ & $40.9 \pm 15.8$ & $0.98(0.93-1.04)$ & $0.99(0.94-1.05)$ \\
\hline \multicolumn{5}{|l|}{ Histological diagnosis } \\
\hline Malignant & $5(14.3)$ & $30(85.7)$ & $1.90(0.51-7.09)$ & $1.42(0.26-7.80)$ \\
\hline Benign & $5(8.1)$ & $57(91.9)$ & & \\
\hline
\end{tabular}

All values are mean \pm standard deviation or number (percentage) unless indicated otherwise. ${ }^{*}$ None of the covariates was statistically significant (at $p$ value $<0.05$ ). ${ }^{a}$ Comorbidities included diabetes mellitus and chronic kidney disease. CI, confidence intervals.

Several studies have investigated the role of prophylactic antibiotics in noncardiac thoracic surgery, using different antimicrobial agents for varying durations (Table 4). In the first reported, randomized, controlled trial, Kvale et al. [18] found that the use of a 5-day course of antibiotics (cefazolin followed by cephalexin) resulted in a significantly smaller number of postoperative infections after pulmonary resections. In another study, in which prophylactic antibiotics (cefazolin followed by cephalothin) were administered for $48 \mathrm{~h}$, no difference in the incidence of postoperative infections was observed between the drug and the placebo groups [19]. In yet another study in 200 patients undergoing major thoracic surgery, a single dose of cefuroxime $1.5 \mathrm{~g}$ did not reduce infections of the wound, pleural space, and urinary tract significantly compared with placebo [7]. In a study by Aznar et al. [5], a single preoperative dose of $1 \mathrm{~g}$ of cefazolin was compared to placebo in patients undergoing thoracic surgery. Cefazolin reduced the incidence of wound infection significantly (1.5\% in the antibiotic group vs. $14 \%$ in the placebo group) but not the incidence of empyema ( 7 vs. $14 \%$ in the antibiotic and placebo group, respectively).

In the current study, we used a protocol of a single preprocedural dose of cefazolin (though with a higher dose of $2 \mathrm{~g}$ ) similar to that of Aznar et al. [5], but did not find a difference in the incidence of wound or pleural space infection. The overall incidence of surgical site infections
(4\%) and empyema (6\%) in the entire study population of the current study was lower than that reported in the study by Aznar et al. [5]. This is because medical thoracoscopy is generally a much shorter and less extensive procedure than thoracic surgery. Moreover, it is performed through a single small incision, thus the overall risk of wound infection is possibly low. Whether there is a true futility of using a preprocedural single dose of antibiotics or whether it is the smaller number of events in the current study that prevented us from detecting any difference between the groups cannot be determined.

We also did not identify any other variables that may potentially be associated with the occurrence of a postprocedural infection (including age, comorbid illnesses, duration of procedure, type of thoracoscope used, and diagnosis of a malignancy on histology) in a multivariate logistic regression analysis. The median (IQR) duration of postprocedural intercostal tube drainage in the present study was relatively long, i.e., 4 (2-10) days; an intercostal tube could have acted as a conduit for pleural space infection. However, we did not include postprocedural drainage duration as a factor in the multivariate analysis as prolonged drainage may either be the cause or the effect of pleural space infection. One might wonder whether the prolonged presence of an intercostal drainage tube might nullify the effect of a single dose of antimicrobial administered in the preprocedural period and a rather pro- 
Table 4. Randomized, controlled trials evaluating prophylactic antibiotics in noncardiac thoracic surgery

\begin{tabular}{|c|c|c|c|c|c|}
\hline Reference & Year & $\begin{array}{l}\text { Subjects, } \\
n\end{array}$ & $\begin{array}{l}\text { Type of surgical } \\
\text { procedure }\end{array}$ & Study groups & Findings \\
\hline Kvale et al. [18] & 1977 & 77 & $\begin{array}{l}\text { Pulmonary } \\
\text { resection }\end{array}$ & $\begin{array}{l}\text { Single dose cefazolin } 500 \mathrm{mg} \text { IM } \\
\text { preoperatively followed by cephalexin } \\
500 \mathrm{mg} \text { PO q6h vs. placebo for } 5 \text { days }\end{array}$ & $\begin{array}{l}\text { Infections in } 19 \% \text { in the } \\
\text { antibiotic group vs. } 50 \% \text { in } \\
\text { the placebo group }(p=0.005)\end{array}$ \\
\hline Truesdale et al. [19] & 1979 & 57 & $\begin{array}{l}\text { Noncardiac } \\
\text { thoracic surgery }\end{array}$ & $\begin{array}{l}\text { Single dose cefazolin } 1 \mathrm{~g} \text { IM } \\
\text { preoperatively followed by } 8 \text { doses of } \\
\text { cephalothin } 2 \mathrm{~g} \text { IV over } 48 \mathrm{~h}\end{array}$ & $\begin{array}{l}\text { Infections in } 17.8 \% \text { in the } \\
\text { antibiotic group vs. } 17.2 \% \text { in } \\
\text { the placebo group }\end{array}$ \\
\hline Cameron et al. [20] & 1981 & 171 & $\begin{array}{l}\text { Pulmonary } \\
\text { resection }\end{array}$ & $\begin{array}{l}\text { Four doses of cephalothin } 2 \mathrm{~g} \text { IV vs. } \\
\text { no antibiotic }\end{array}$ & $\begin{array}{l}\text { No difference in } \\
\text { postoperative septic } \\
\text { complications in the } \\
\text { antibiotic vs. the control } \\
\text { group }(25.0 \text { vs. } 31.3 \%)\end{array}$ \\
\hline Ilves et al. [21] & 1981 & 211 & $\begin{array}{l}\text { Major elective } \\
\text { general thoracic } \\
\text { operations }\end{array}$ & $\begin{array}{l}\text { Two doses of cephalothin } 2 \mathrm{~g} \text { IV vs. } \\
\text { placebo }\end{array}$ & $\begin{array}{l}\text { Antibiotic effective in } \\
\text { reducing superficial ( } 5.1 \text { vs. } \\
18.3 \% ; p<0.01 \text { ) and deep } \\
\text { wound ( } 0.8 \text { vs. } 5.4 \% ; p<0.05 \text { ) } \\
\text { infections; empyema } \\
\text { incidence unaffected ( } 4.2 \text { vs. } \\
6.5 \% ; p>0.05)\end{array}$ \\
\hline $\begin{array}{l}\text { Frimodt-Moller } \\
\text { et al. [22] }\end{array}$ & 1982 & 92 & $\begin{array}{l}\text { Elective } \\
\text { thoracotomy } \\
\text { with possible } \\
\text { pulmonary } \\
\text { resection }\end{array}$ & $\begin{array}{l}\text { Six doses of penicillin G } 5 \text { million IU } \\
\text { IV q6h or placebo }\end{array}$ & $\begin{array}{l}\text { Total infections ( } 37.8 \text { vs. } \\
59.6 \% ; p=0.04 \text { ) and wound } \\
\text { infections ( } 4.4 \text { vs } 19.1 \% ; p= \\
0.03 \text { ) lower in the antibiotic } \\
\text { group; empyema similar ( } 4.4 \\
\text { vs. } 4.3 \%)\end{array}$ \\
\hline Tarkka et al. [23] & 1987 & 120 & $\begin{array}{l}\text { Elective } \\
\text { thoracotomy } \\
\text { and probable } \\
\text { pulmonary } \\
\text { resection }\end{array}$ & $\begin{array}{l}\text { Doxycycline } 200 \mathrm{mg} \text { PO } 1 \text { day } \\
\text { preoperatively, } 100 \mathrm{mg} \text { doxycycline IV } \\
\text { intraoperatively followed by } \\
\text { doxycycline } 100 \mathrm{mg} / \text { day PO for } 3 \text { days } \\
\text { postoperatively vs. cefuroxime } 1.5 \mathrm{~g} \mathrm{IV} \\
\text { intraoperatively followed by } 0.75 \mathrm{~g} \text { q } 8 \mathrm{~h} \\
\text { for } 3 \text { days }\end{array}$ & $\begin{array}{l}\text { Incidence of infections } 31.7 \% \\
\text { in the doxycycline group vs. } \\
16.7 \% \text { in the cefuroxime } \\
\text { group }(p=0.055)\end{array}$ \\
\hline Regnard et al. [24] & 1989 & 171 & Pneumonectomy & $\begin{array}{l}\text { Minocycline } 200 \mathrm{mg} / \text { day for } 7 \text { days } \\
\text { with saline irrigation vs. } 3 \text { doses of } \\
\text { cefotiam with iodine-povidone } \\
\text { irrigation }\end{array}$ & $\begin{array}{l}\text { Empyema: } 10.5 \% \text { in the } \\
\text { minocycline-saline group vs. } \\
3.5 \% \text { in the cefotiam-iodine } \\
\text { group }\end{array}$ \\
\hline Aznar et al. [5] & 1991 & 127 & $\begin{array}{l}\text { Noncardiac } \\
\text { thoracic surgery }\end{array}$ & $\begin{array}{l}\text { Single preoperative dose of cefazolin } \\
1 \mathrm{~g} \text { IV vs. placebo }\end{array}$ & $\begin{array}{l}\text { Infections: cefazolin }(17 \%) \text { vs. } \\
\text { placebo }(48 \% ; p<0.002) \\
\text { Wound infections: cefazolin } \\
\text { group }(1.5 \%) \text { vs. placebo } \\
(14 \% ; p<0.01) \\
\text { Empyema: cefazolin }(7 \%) \text { vs. } \\
\text { placebo }(14 \%) \\
\text { Nosocomial pneumonia: } \\
\text { cefazolin }(4 \%) \text { vs. placebo } \\
(9 \%)\end{array}$ \\
\hline Krasnik et al. [25] & 1991 & 94 & $\begin{array}{l}\text { Elective } \\
\text { thoracotomy } \\
\text { with possible } \\
\text { pulmonary } \\
\text { resection }\end{array}$ & $\begin{array}{l}\text { Penicillin G } 5 \text { million U IV or } \\
\text { cefuroxime } 1.5 \mathrm{~g} \text { IV q } 8 \mathrm{~h} \text { for } 4 \text { doses } \\
\text { (first dose immediately before surgery) }\end{array}$ & $\begin{array}{l}\text { No significant difference in } \\
\text { the incidence of total } \\
\text { infections, wound infections, } \\
\text { or empyema }(p=0.14)\end{array}$ \\
\hline
\end{tabular}

Respiration 2017;94:207-215
DOI: $10.1159 / 000477259$
Dhooria/Sehgal/Prasad/Bal/Aggarwal/ Behera/Agarwal 
Table 4 (continued)

\begin{tabular}{|c|c|c|c|c|c|}
\hline Reference & Year & $\begin{array}{l}\text { Subjects, } \\
n\end{array}$ & $\begin{array}{l}\text { Type of surgical } \\
\text { procedure }\end{array}$ & Study groups & Findings \\
\hline Olak et al. [26] & 1991 & 208 & $\begin{array}{l}\text { Thoracotomy and } \\
\text { lung resection }\end{array}$ & $\begin{array}{l}\text { Single dose cefazolin } 1 \mathrm{~g} \text { IV } \\
\text { preoperatively followed by } 5 \text { doses of } \\
\text { placebo q8h vs. single dose cefazolin } \\
1 \mathrm{~g} \text { IV preoperatively followed by } 5 \\
\text { further doses }(1 \mathrm{~g} \mathrm{IV}) \mathrm{q} 8 \mathrm{~h}\end{array}$ & $\begin{array}{l}\text { No difference in incidence of } \\
\text { postoperative infections in } \\
\text { the single dose group vs. the } \\
\text { six-dose group ( } 11.1 \text { vs. } 13 \% \text { ) }\end{array}$ \\
\hline Wertzel et al. [27] & 1992 & 60 & $\begin{array}{l}\text { Lobectomy or } \\
\text { segmentectomy }\end{array}$ & $\begin{array}{l}\text { Single dose ampicillin-sulbactam } 3 \mathrm{~g} \\
\text { vs. } 3 \mathrm{~g} \text { q } 8 \mathrm{~h} \text { for } 3 \text { doses }\end{array}$ & $\begin{array}{l}\text { No difference in the incidence } \\
\text { of postoperative infections } \\
\text { between the single-dose } \\
\text { regimen }(50 \%) \text { vs. the three- } \\
\text { dose }(33.3 \%) \text { regimen }\end{array}$ \\
\hline Frey et al. [7] & 1993 & 200 & $\begin{array}{l}\text { Major thoracic } \\
\text { surgery }\end{array}$ & $\begin{array}{l}\text { Single dose cefuroxime } 1.5 \mathrm{~g} \text { IV vs. } \\
\text { no antibiotic }\end{array}$ & $\begin{array}{l}\text { No significant difference in } \\
\text { the infections of the wound, } \\
\text { pleural cavity, or urinary tract }\end{array}$ \\
\hline Bernard et al. [28] & 1994 & 203 & $\begin{array}{l}\text { Thoracotomy } \\
\text { with lung } \\
\text { resection }\end{array}$ & $\begin{array}{l}\text { Two perioperative doses of cefuroxime } \\
1.5 \mathrm{~g} \text { IV vs. } 2 \text { perioperative doses plus } \\
1.5 \mathrm{~g} \text { IV q6h for } 48 \mathrm{~h}\end{array}$ & $\begin{array}{l}\text { Overall rate of infections less } \\
\text { in } 48 \text { h group compared to } \\
\text { the other group ( } 46 \text { vs. } 65 \% \text {; } \\
p=0.005 \text { ) }\end{array}$ \\
\hline Boldt et al. [29] & 1999 & 120 & $\begin{array}{l}\text { Elective } \\
\text { pulmonary } \\
\text { resections }\end{array}$ & $\begin{array}{l}\text { Single dose ampicillin-sulbactam } 1.5 \mathrm{~g} \\
\text { IV vs. cefazolin } 2 \mathrm{~g} \text { IV }\end{array}$ & $\begin{array}{l}\text { Significantly more infections } \\
\text { in the cefazolin group vs. the } \\
\text { ampicillin-sulbactam group }\end{array}$ \\
\hline Turna et al. [6] & 2003 & 102 & $\begin{array}{l}\text { Elective } \\
\text { thoracotomy }\end{array}$ & $\begin{array}{l}\text { Cefuroxime } 1.5 \mathrm{~g} \text { IV q12h vs. cefepime } \\
1 \mathrm{~g} \text { IV for } 24 \mathrm{~h}\end{array}$ & $\begin{array}{l}\text { Overall infection rates } 14.0 \% \\
\text { in the cefuroxime group vs. } \\
26.7 \% \text { in the cefepime group } \\
(p=0.12)\end{array}$ \\
\hline Oxman et al. [30] & 2013 & 245 & $\begin{array}{l}\text { Elective thoracic } \\
\text { surgery requiring } \\
\text { tube thoracostomy }\end{array}$ & $\begin{array}{l}\text { Cefazolin } 1 \mathrm{~g} \text { IV (or } 2 \mathrm{~g} \text { for body } \\
\text { weight }>80 \mathrm{~kg} \text { ) vs. placebo q } 8 \mathrm{~h} \text { for } 48 \mathrm{~h} \\
\text { or until all chest tubes were removed, } \\
\text { whichever occurred first }\end{array}$ & $\begin{array}{l}\text { Incidence of infections } 10.7 \% \\
\text { in the intervention group vs. } \\
6.5 \% \text { in the placebo group } \\
(p=0.26)\end{array}$ \\
\hline
\end{tabular}

IM, intramuscular; IV, intravenous; PO, per oral.

longed course of antibiotics might be warranted. In this context, however, even the prolonged use of an antimicrobial may not be effective in preventing infections in such patients as evident from a recent study. In this study, an extended antibacterial prophylaxis (administered for $48 \mathrm{~h}$ or until all thoracostomy tubes were removed) was compared to placebo in patients undergoing elective thoracic surgery. All patients in both the study groups received preoperative prophylaxis with cefazolin. The extended prophylaxis did not reduce the incidence of postoperative infections in the antimicrobial group as compared to placebo [30].

The overall incidence of complications ( $10 \%$ infections) was fairly high in this study when compared to ear- lier reports of medical thoracoscopy [4]. Most of our patients present late to our center; notably, the median duration of symptoms at the time of thoracoscopy among subjects in the present study was 2 months. Almost 50\% of the study subjects had dense adhesions in the pleura. This not only makes medical thoracoscopy procedurally difficult and time-consuming but it may also occasionally result in a failure to obtain a pleural biopsy, as occurred in 3 subjects in our study, despite the use of pointof-care ultrasonography. Some subjects have a thick visceral pleural peel which cannot be removed during medical thoracoscopy and which requires a more extensive procedure such as video-assisted thoracic surgery that is not available at our center. This is one of the major 
reasons for prolonged intercostal tube drainage and failure of the lung to expand following the procedure with subsequently increased risk of infections.

Clinical practice guidelines for antimicrobial prophylaxis in surgery recommend a single dose of cefazolin or ampicillin-sulbactam in patients undergoing thoracic procedures [8]. The same recommendation cannot be extrapolated to patients undergoing medical thoracoscopy, going by the results of the current study. Thoracoscopy is a short procedure that most often involves pleural biopsies only. As the pleural cavity is normally a sterile cavity, the only route of postoperative infections is through the skin and the instruments used during the pleural procedures. If aseptic precautions are closely adhered to, which includes the use of appropriately sterilized instruments, sterile technique, and thorough cleaning of the surgical site with antiseptics, the incidence of infections may be kept to a minimum. The British Thoracic Society guidelines suggest the use of prophylactic antibiotics only in patients with a high risk of complications [1]. In our study, only a small number (13\%) of subjects had comorbidities (diabetes mellitus or chronic kidney disease), and there was no difference in the incidence of infections in this population as compared to those without any comorbidities. Due to the small numbers, the utility of using prophylactic antimicrobials in these populations cannot be definitely decided. Larger studies are required with different antibiotic agents given for different durations to clarify the role of prophylactic antibiotics in this setting.

In conclusion, the routine use of a single dose of a prophylactic antibiotic in patients undergoing medical thoracoscopy does not result in a reduced rate of postprocedural infections.

\section{Disclosure Statement}

None of the authors has any potential conflicts of interest to disclose.

\section{References}

1 Rahman NM, Ali NJ, Brown G, Chapman SJ, Davies RJ, Downer NJ, Gleeson FV, Howes TQ, Treasure T, Singh S, Phillips GD: Local anaesthetic thoracoscopy: British Thoracic Society Pleural Disease Guideline 2010. Tho$\operatorname{rax}$ 2010;65(Suppl 2):ii54-ii60.

2 Lee P, Colt HG: Rigid and semirigid pleuroscopy: the future is bright. Respirology 2005; 10:418-425.

3 Agarwal R, Aggarwal AN, Gupta D: Diagnostic accuracy and safety of semirigid thoracoscopy in exudative pleural effusions: a metaanalysis. Chest 2013;144:1857-1867.

4 Wang XJ, Yang Y, Wang Z, Xu LL, Wu YB, Zhang J, Tong ZH, Shi HZ: Efficacy and safety of diagnostic thoracoscopy in undiagnosed pleural effusions. Respiration 2015;90:251255.

5 Aznar R, Mateu M, Miro JM, Gatell JM, Gimferrer JM, Aznar E, Mallolas J, Soriano E, Sanchez-Lloret J: Antibiotic prophylaxis in noncardiac thoracic surgery: cefazolin versus placebo. Eur J Cardiothorac Surg 1991;5: 515-518.

6 Turna A, Kutlu CA, Ozalp T, Karamustafaoglu A, Mulazimoglu L, Bedirhan MA: Antibiotic prophylaxis in elective thoracic surgery: cefuroxime versus cefepime. Thorac Cardiovasc Surg 2003;51:84-88.

7 Frey DJ, Reichmann AK, Mauch H, Kaiser D: "Single-shot" antibiotic prophylaxis in thoracic surgery; reduction of the postoperative infection rate (article in German). Infection 1993;21(suppl 1):S35-S44.
8 Bratzler DW, Dellinger EP, Olsen KM, Perl TM, Auwaerter PG, Bolon MK, Fish DN, Napolitano LM, Sawyer RG, Slain D, Steinberg JP, Weinstein RA: Clinical practice guidelines for antimicrobial prophylaxis in surgery. Surg Infect (Larchmt) 2013;14:73-156.

9 Blanc FX, Atassi K, Bignon J, Housset B: Diagnostic value of medical thoracoscopy in pleural disease: a 6-year retrospective study. Chest 2002;121:1677-1683.

10 Marchetti G, Valsecchi A, Indellicati D, Arondi S, Trigiani M, Pinelli V: Ultrasound-guided medical thoracoscopy in the absence of pleural effusion. Chest 2015;147:1008-1012.

11 Grendelmeier P, Tamm M, Jahn K, Pflimlin E, Stolz D: Propofol versus midazolam in medical thoracoscopy: a randomized, noninferiority trial. Respiration 2014;88:126-136.

12 Mohan A, Naik S, Naseer R, Boon C, Mills J, Pandey RM, Munavvar M: Performance characteristics of semirigid thoracoscopy in pleural effusions of undetermined etiology. J Bronchology Interv Pulmonol 2010;17:289294.

13 Prabhu VG, Narasimhan R: The role of pleuroscopy in undiagnosed exudative pleural effusion. Lung India 2012;29:128-130.

14 Mootha VK, Agarwal R, Singh N, Aggarwal AN, Gupta D, Jindal SK: Medical thoracoscopy for undiagnosed pleural effusions: experience from a tertiary care hospital in north India. Indian J Chest Dis Allied Sci 2011;53: 21-24.
15 Dhooria S, Singh N, Aggarwal AN, Gupta D, Agarwal R: A randomized trial comparing the diagnostic yield of rigid and semirigid thoracoscopy in undiagnosed pleural effusions. Respir Care 2014;59:756-764.

16 Maturu VN, Dhooria S, Bal A, Singh N, Aggarwal AN, Gupta D, Behera D, Agarwal R: Role of medical thoracoscopy and closedblind pleural biopsy in undiagnosed exudative pleural effusions: a single-center experience of 348 patients. J Bronchology Interv Pulmonol 2015;22:121-129.

17 Maturu VN, Sehgal IS, Dhooria S, Bal A, Aggarwal AN, Behera D, Agarwal R: Pleuroscopic cryobiopsy: case series and systematic review. J Bronchology Interv Pulmonol 2015; 22:e11-e13.

18 Kvale PA, Ranga V, Kopacz M, Cox F, Magilligan DJ, Davila JC: Pulmonary resection. South Med J 1977;70(suppl 1):64-68.

19 Truesdale R, D’Alessandri R, Manuel V, Daicoff G, Kluge RM: Antimicrobial versus placebo prophylaxis in noncardiac thoracic surgery. JAMA 1979;241:1254-1256.

20 Cameron JL, Imbembo A, Kieffer RF, Spray S, Baker RR: Prospective clinical trial of antibiotics for pulmonary resections. Surg Gynecol Obstet 1981;152:156-158.

21 Ilves R, Cooper JD, Todd TR, Pearson FG: Prospective, randomized, double-blind study using prophylactic cephalothin for major, elective, general thoracic operations. J Thorac Cardiovasc Surg 1981;81:813-817. 
22 Frimodt-Moller N, Ostri P, Pedersen IK, Poulsen SR: Antibiotic prophylaxis in pulmonary surgery: a double-blind study of penicillin versus placebo. Ann Surg 1982;195:444450.

23 Tarkka M, Pokela R, Lepojarvi M, Nissinen J, Karkola P: Infection prophylaxis in pulmonary surgery: a randomized prospective study. Ann Thorac Surg 1987;44:508-513.

24 Regnard JF, Libert JM, Rojas-Miranda A, Marzelle J, Levasseur P: Antibiotic and antiseptic prophylaxis in thoracic surgery. Controlled study (article in French). Pathol Biol (Paris) 1989;37:477-480.

25 Krasnik M, Thiis J, Frimodt-Moller N: Antibiotic prophylaxis in non-cardiac thoracic surgery. A double-blind study of penicillin vs. cefuroxime. Scand J Thorac Cardiovasc Surg 1991;25:73-76.
26 Olak J, Jeyasingham K, Forrester-Wood C, Hutter J, al-Zeerah M, Brown E: Randomized trial of one-dose versus six-dose cefazolin prophylaxis in elective general thoracic surgery. Ann Thorac Surg 1991;51:956-958.

27 Wertzel H, Swoboda L, Joos-Wurtemberger A, Frank U, Hasse J: Perioperative antibiotic prophylaxis in general thoracic surgery. Thorac Cardiovasc Surg 1992;40:326-329.

28 Bernard A, Pillet M, Goudet P, Viard H: Antibiotic prophylaxis in pulmonary surgery. A prospective randomized double-blind trial of flash cefuroxime versus forty-eight-hour cefuroxime. J Thorac Cardiovasc Surg 1994;107: 896-900.
29 Boldt J, Piper S, Uphus D, Fussle R, Hempelmann G: Preoperative microbiologic screening and antibiotic prophylaxis in pulmonary resection operations. Ann Thorac Surg 1999; 68:208-211.

30 Oxman DA, Issa NC, Marty FM, Patel A, Panizales CZ, Johnson NN, Licona JH, McKenna SS, Frendl G, Mentzer SJ, Jaklitsch MT, Bueno R, Colson Y, Swanson SJ, Sugarbaker DJ, Baden LR: Postoperative antibacterial prophylaxis for the prevention of infectious complications associated with tube thoracostomy in patients undergoing elective general thoracic surgery: a double-blind, placebocontrolled, randomized trial. JAMA Surg 2013;148:440-446. 